\title{
Hombres, mujeres y nación: representaciones en medios impresos durante la dictadura stronista en Paraguay (año 1959)
}

Men, women and nation: media representation during the Stroessner dictatorship in Paraguay (1959)

Homens, mulheres e nação: representações na mídia impressa durante a ditadura stronista no Paraguai (1959)

\footnotetext{
Aníbal ORUÉ POZZO

Centro de Estudios Rurales Interdisciplinarios, Paraguay / aoruepozzo@gmail.com

Florencia FALABELLA

Centro de Estudios Rurales Interdisciplinarios, Paraguay /

ffalabellad@gmail.com
}

\footnotetext{
Chasqui. Revista Latinoamericana de Comunicación

N. ${ }^{o}$ 135, agosto - noviembre 2017 (Sección Monográfico, pp. 71-87)

ISSN 1390-1079 / e-ISSN 1390-924X

Ecuador: CIESPAL

Recibido: 21-05-2017 / Aprobado: 23-08-2017
} 


\title{
Resumen
}

Tomando como eje estructurante contenidos del diario El País (setiembre-diciembre, 1959) relacionados a la muerte del locutor y periodista Bernardo Aranda, el artículo discute, desde la categoría de género, las representaciones e imaginarios impulsados por dicho medio en relación a la idea de nación. A partir de la construcción de dos matrices semánticas asociadas a los temas: i) juventud y música rock and roll, y ii) disciplina y posturas viriles, el texto interpreta cómo y de qué manera específica esta construcción se manifiesta.

Palabras clave: Bernardo Aranda; género; imaginarios; política, periodismo.

\begin{abstract}
Assuming as structural axis the newspaper El País content's (SeptemberDecember, 1959) related to the death of the journalist Bernardo Aranda, the article discuss from a gender perspective, representations and imaginaries regarding how this media introduce the idea of nation. The text selected two semantic matrix associated with: i) youth and rock and roll music, and ii) Discipline and virile postures, and develop an interpretation of how and in what specific way this idea of nation building is manufactured.
\end{abstract}

Keyword: Bernardo Aranda; gender; imaginaries; politics; journalism.

\section{Resumo}

Tendo como eixos estruturantes conteúdos do jornal El País (setembro-dezembro, 1959) relacionados à morte do locutor e jornalista Bernardo Aranda, o artigo propõe uma discussão tanto a respeito das categorias de gênero quanto às representações e imaginários fomentados pelo jornal, relacionado-os à ideia de nação. A partir da constituição de duas matrizes semânticas associadas aos temas: i) juventude e rock and roll e; ii) disciplinas e posturas viris, o texto interpreta como e de que forma específica tal construção se manifesta.

Palavras-chave: Bernardo Aranda; gênero; imaginários; política; jornalismo. 


\section{Introducción}

El presente artículo tiene por objetivo estudiar y analizar, desde una perspectiva de género, cómo los ideales de hombre y mujer, así como los roles de género contenidos dentro del concepto de nación que se reflejan en la narrativa de diario El País -a partir de la muerte del locutor y periodista Bernardo Aranda en setiembre de 1959-, fueron utilizados por la emergente dictadura stronista como parte de un proceso de consolidación de su poder y control político. La muerte de Bernardo Aranda, desata una de las primeras represiones masivas del stronismo bajo la supuesta acusación de pertenecer a una organización de "amorales", "desviados" u homosexuales, interesados en ocultar u obstruir el normal desarrollo de la investigación policial y judicial. Varias instituciones de la sociedad paraguaya -Poder Judicial, Policía y medios de comunicación- se "unen" de manera a reforzar aquellos modelos de hombre y mujer y los roles de género ya existentes, así como la idea de nación caracterizada por un fuerte contenido androcentrista.

A lo largo de aproximadamente cuatro meses, El País, medio impreso estrechamente vinculado a la dictadura, construye una narrativa en la cual asocia la homosexualidad a la perversión, a comportamientos "desviados" y "amorales", asimismo a prácticas subversivas que son introducidas desde fuera del país. La mujer, ausente en gran parte de esta narrativa, está representada más por su ausencia que por su explícita presencia. Esto sucede a escasos cinco años de vida de la dictadura -que se inicia en mayo de 1954. A partir de entonces, la "invención" de un modelo desarrollado por el aparato policial paraguayo durante el proceso de investigación de la muerte de Aranda se convierte en un modelo perfeccionado seguido sistemáticamente a lo largo de más de 30 años de dictadura.

Los modelos masculinos y femeninos impulsados por la dictadura, necesitan insertarse y extenderse a todos los ámbitos de la sociedad paraguaya. Hombres y mujeres, deben reunir los requisitos de comportamiento viril -para hombresy femenino -para el caso de las mujeres-, y el mismo debe ser impuesto inclusive a la fuerza, a través de una activa violencia sobre los cuerpos de las personas. Este artículo, a partir del proceso de "búsqueda del asesino" de Bernardo Aranda por la Policía paraguaya y el Poder Judicial, discute la construcción de los ideales de hombre y de mujer a través de la narrativa del medio impreso y su relación con la nación paraguaya.

A lo largo de la cobertura periodística, se destaca la estrecha relación existente entre el medio de comunicación impreso, la Policía y el Poder Judicial, asumiendo el medio mencionado, un papel de estrecho colaborador de la justicia, es decir, se convierte en un amplificador de los intereses y posturas del estado. 


\section{Contexto social y político}

En mayo de 1954, un golpe de Estado cívico-militar encabezado por Alfredo Stroessner inicia una de las más largas y violentas dictaduras que ha conocido Paraguay. Poco tiempo después, y con el apoyo de la Asociación Nacional Republicana (Partido Colorado) -en elecciones en las que participa únicamente esta fracción política-, Stroessner es electo presidente de la República.

Cinco años después y luego de varios intentos de control social y político por parte de este gobierno, la dictadura consigue domesticar, por un lado, e higienizar, por el otro, a sectores críticos del Partido Colorado que inicialmente lo habían apoyado, pero que van separándose de ella. Entre mayo y agosto de 1959, Stroessner y sus aliados consiguen avanzar en su proyecto de legitimidad de la fuerza, logrando eliminar en parte a sectores de oposición dentro del Partido Colorado. Con esto el stronismo consigue controlar no solo el aparato militar sino también el político del Partido Colorado (Junta de Gobierno, s/f).

Una huelga estudiantil detonada en mayo de 1959 por el costo del pasaje, provoca una reacción de este segmento social al mismo tiempo que impulsa una serie de solidaridades tanto en sectores opositores como en el interior del propio Partido Colorado. Ante esta situación, la denominada Junta de Gobierno del Partido Colorado -instrumento de conducción partidaria y base política de apoyo de Stroessner para el golpe de 1954- se quiebra. El emergente stronismo aprovecha para asumir el control más amplio de este espacio de poder partidario, expulsando a unos, cooptando a otros, neutralizando a terceros, reconstruyendo así esta instancia del poder político (Coronel, 2013). En octubre de ese mismo año, se dan los primeros intentos de ingreso al país de militantes del Movimiento Guerrillero 14, de Mayo, que habían asumido la vía armada como forma de lucha contra la dictadura stronista; el Frente Unido de Liberación Nacional (FULNA), otra organización que impulsó la lucha armada contra la dictadura comienza a expresarse de manera más abierta en el país. Son detectados varios focos de oposición a la dictadura cívico-militar, expulsiones por un lado, y acciones de sectores de oposición en varios puntos de la Argentina, frontera con Paraguay (Céspedes \& Paredes, 2004; Duré \& Silva, 2004).

En medio de esta agitación política, la dictadura aprovecha para consolidar y ampliar sus espacios sociales y políticos, reprimiendo ambos movimientos al exterior, asimismo al interior del Partido Colorado. Pero no solamente el momento es aprovechado para eliminar grupos políticos de oposición, también para imponer autoritariamente formas o maneras de comportamiento social, orientando cómo y de qué manera el cuerpo debe ser "usado". La dictadura estimula y promueve un proceso al que denominamos domesticación del cuerpo. En este contexto, la muerte del locutor, Bernardo Aranda, en la madrugada del $1 \mathrm{de}$ setiembre de 1959, constituye una variable que contribuye a domesticar los cuerpos, la moral y las buenas costumbres, de la entonces sociedad asuncena y paraguaya; asimismo, un hecho político de no menor importancia que los anteriores 
citados: esta muerte es hábilmente aprovechada por la dictadura para impulsar otros ejes en la construcción imaginaria de un modelo de país, necesario para el momento que se estaba viviendo y de convertirse en la primera gran represión masiva del stronismo a pocos años de su instalación.

La década de 1950 introduce cambios en la población paraguaya, reconfigurándola en aspectos vinculados al género. El Censo de 1950 apuntaba un pequeño margen de diferencia entre hombres y mujeres; el índice de escolaridad de las mujeres aumentaba rápidamente. Los medios de comunicación impresos expresaban estas transformaciones incorporando desde fines de los '5o e inicios de los años '6o del siglo XX una sección dedicada a la mujer. Un cambio significativo que permitiría, en poco tiempo, aumentar la venta del producto impreso. La publicidad, como una de las maneras institucionales de construir imaginarios, daba sus primeros pasos con la creación de agencias que colocaban avisos comerciales destacando un determinado modo de ser mujer, un determinado modo o forma de ser hombre, usos del cuerpo, etc. El periodismo paraguayo estaba pasando por un momento de transición entre aquella tradición que respondía a partidos u organizaciones políticas, y la emergente postura de independencia de éstos, es decir, el desprendimiento de sus relaciones político-partidarias y el vuelco al mercado. Los textos periodísticos expresaban en este momento la hibridez de estos cambios. En los mismos convivían en un mismo material opiniones, hechos y datos, todos ellos organizados en una narrativa híbrida, expresión también de los cambios mencionados (Orué Pozzo, 2007).

En este sentido la década de los '5o trae al país cambios importantes, sea en el plano económico, en el social, en el político, asimismo en medios de comunicación y en la construcción del género en Paraguay. En 1954, con la asunción de Stroessner a la presidencia, se fortalece este proceso: el Partido Colorado se consolida, juntamente con el ejército, como instituciones que garantizan el esquema de dominación hegemónica en el país.

\section{Género, dictadura y la muerte de Aranda}

La perspectiva de estudio adoptada, introduce y piensa al género como una categoría analítica fundamental para entender y comprender la construcción imaginaria de la nación durante los primeros años del stronismo. Igualmente, busca hurgar en cómo y de qué manera esa construcción de la nación refuerza los modelos de género vigentes, y los ideales de lo que debe ser un hombre paraguayo y una mujer paraguaya, al mismo tiempo que la construye como una narrativa más en el proceso de consolidación y fortalecimiento de la dictadura, entendida ésta como un sistema político que controla y domestica comportamientos y cuerpos, tanto de hombres como de mujeres, justificando la subordinación de la mujer.

La investigación se ha sustentado en varias autoras que han trabajado el campo teórico del feminismo y de los movimientos LGTBI. Para el presente 
artículo hemos recurrido a trabajos de J. Scott (1996), Preciado (2008) y Wittig (2006). Asimismo, la investigación fue pensada desde una perspectiva que, siendo crítica a las anteriores, introduce consideraciones desde el locus de enunciación, es decir, desde movimientos feministas y LGTBI de América Latina -indígenas, afrodescendientes y otros sectores subalternos- en una perspectiva que enfatiza producciones teóricas del feminismo latinoamericano como es el caso de Lugones (2014; 2010), Bidasecas (2014), Bidasecas y Serra (2014), Segato (2014) y Costa Lima (2014). Por otro lado, se ha consultado la bibliografía paraguaya sobre el discurso feminista y género que, si bien es una tradición que lleva varias décadas de estar presente en el escenario nacional, fue sumamente descuidada y omitida por el pensamiento académico y social, ignorándola sistemáticamente. Es el caso de Dávalos (2007 [1907]), Corvalán (1994), Bareiro, Soto y Monte (1994) y Silveira (1994). Consideramos que estos aportes constituyen piedras fundamentales para la construcción de un discurso y una práctica que conducen a una sociedad más equitativa. Finalmente, en los últimos años se han producidos algunos trabajos que introducen cuestionamientos al tratamiento binario sexo-género que consideramos un aporte importante para el presente material. En este contexto se tienen los trabajos de Falabella (2012), Duré (2012) y Villalba (2009a; 2009b). Igualmente, en cuanto a situaciones y dominios desde el poder, hemos examinado la perspectiva de diversos autores que sustentan reflexiones desde la inflexión o giro decolonial, como es el caso de Quijano (2000), Mignolo (2003) y Castro Gómez \& Grosfogel (2007).

En relación al caso específico de Bernardo Aranda y la perspectiva de género adoptada, es relativamente poco lo que se ha escrito sobre el tema; algunos son escritos en passant sin investigaciones empíricas que lo sustenten, otros, relatos más autobiográficos. Sin embargo, tenemos un trabajo pionero en este campo que, sin duda alguna, constituye un material sumamente valioso y que abre caminos para otros entendimientos e investigaciones. Es el trabajo de Erwing Augsten Szokol, (2013). Además, otras producciones que, desde diversas perspectivas, inclusive desde la creación literaria (literatura, teatro) abordan el tema. Es el caso de Carbone (2014), Neri Farina (2010), Almada Roche (2012), Nuñez (2001) y la tesis de maestría de Clara Cuevas (2015). El informe de la Comisión Verdad y Justicia (2008) incluye también un apartado especial sobre el tema, aunque desde una perspectiva distinta.

\section{Construyendo la Nación}

Son pocos los trabajos publicados que tienen como sujeto la construcción de la nación paraguaya a partir de sus diversos actores sociales desde una perspectiva no eurocéntrica. Sin embargo, en una tenue línea de quiebre de este paradigma, es factible destacar el trabajo de Céspedes (2016) el cual incluye varios textos que desde una construcción de imaginarios de mujer y otros imaginarios urbanos, 
introduce la posibilidad de despegarse de la construcción del Estado-nación paraguayo como una continuidad de aquel que emerge en Europa como resultado de los procesos coloniales iniciados en 1492.

En el presente texto se analiza, la familia, como institución bien ordenada, establecida como modelo social a seguir, que se constituye al mismo tiempo como una estrategia de consolidación de una determinada forma política, social y económica del Estado paraguayo. La familia debe ser orgánica a la nueva forma de gobierno propuesta, es decir, al stronismo. Hombres y mujeres deben asumir un determinado tipo de comportamiento social, que fortalezca este modelo familiar y cristiano. Comportamientos en las márgenes, en las fronteras de este modelo, no pueden ser permitidos y, en consecuencia, deben ser combatidos y domesticados. En este sentido, la mujer construye la nación desde la esfera privada y doméstica, a la cual está supeditada, teniendo nuevos hijos varones y ocupándose del hogar.

\subsection{Género y poder; medio, familia y nación.}

La historiadora feminista, Joan Scott (1996), destaca cómo y de qué manera durante muchos años el género pareció ser irrelevante para cuestiones como sexo o política, familia o nación, mujeres y hombres. Para una parte importante de los estudios, el género parece no aplicarse a hechos históricos de la guerra, la diplomacia y de la alta política. En este sentido, rescatamos que las palabras, como las ideas y las cosas están destinadas a significar y tienen historia. Solo falta explicitarlas.

La discusión sobre la nación, principalmente aquella que emerge a fines del siglo XIX e inicios del siglo XX en Paraguay, tuvo un fuerte contenido androcentrista; fue construida con un componente altamente masculino en las distintas interpretaciones y argumentaciones de la época. Sin embargo, no podemos dejar de mencionar algunos trabajos en los márgenes de dicha construcción hegemónica de la nación, por ejemplo el de Serafina Dávalos (2007 [1907]), Virginia Corvalán (1994) y otras pocas mujeres quienes se encargan de introducir otra perspectiva, en esa idea masculinizada de nación. En este caso, no solo el lugar de la enunciación acaba siendo diferente, sino sobre todo quién lo dice.

El stronismo retoma los desarrollos acerca de la idea de nación y los profundiza. Al retomar los temas y las matrices del nacionalismo y de la nación impulsadas y desarrolladas a inicios del siglo XX en Paraguay, la dictadura stronista estaba dando continuidad al proceso iniciado con la independencia paraguaya. Esta construcción de la nación a partir de una matriz fuertemente masculina, es el proceso que la dictadura impone y desarrolla.

\section{El Caso Aranda y los 108}

Bernardo Aranda fue encontrado muerto, quemado, en una habitación que alquilaba en un barrio de Asunción, el día 1 de setiembre de 1959. Era un joven de 
25 años de edad, locutor de la entonces radio Comuneros. Los medios no aclaran en ningún momento qué tipo de tareas tenía en la radio, ni las características de los programas radiofónicos con los cuales Aranda estaba involucrado. Las primeras conjeturas sobre su muerte apuntaban a un supuesto "crimen pasional" -expresiones de la Policía- por parte de personas de "dudosa conducta moral", ya que existía la sospecha de que él era homosexual.

Apenas unos días después de su muerte, la policía comienza a detener e interrogar de forma arbitraria a un gran número de personas que se presumía eran homosexuales. El 11 de setiembre aparece en el periódico El País el titular: "108 personas de dudosa conducta moral están siendo interrogadas”. Este número, que fue la cantidad aproximada de personas detenidas en la comisaría, y fue calculada por el cronista del periódico, se convirtió a partir de entonces en un calificativo peyorativo para toda persona homosexual. Sin embargo, según datos que el medio va publicando a lo largo de los días, fueron detenidas una cantidad mucho mayor de personas.

El entendimiento que levantan los medios, aquel fuertemente orientado en una relación binaria hombre-mujer, es decir, donde las relaciones sexuales tienen una finalidad reproductiva. Toda relación fuera de estos parámetros era condenada por los medios impresos, entre ellas, la homosexualidad, entendida como "amoral" o como un comportamiento "desviado".

De esta manera, la persecución y represión iniciada por los aparatos policialy judicial dio inicio a una campaña de hostigamiento, violencia y odio hacia personas homosexuales. Se pedía colaboración a toda la ciudadanía para desentrañar e incriminar a la "perversa organización de los amorales" (El País 21/og/1959). A medida que van pasando las semanas se percibe un desplazamiento hacia la criminalización de los "amorales" y la necesidad de reprimirlos pues son vistos como una amenaza social, especialmente para los jóvenes. Tal como indica un lector en una carta enviada a El País: "Quiero pedirle, señor Director, que se inicie una campaña tenaz con toda energía para extirpar este mal que aqueja a la sociedad" (El País 18/o9/1959).

Sin embargo, esta campaña de persecución a los homosexuales encontró una dificultad jurídica: la homosexualidad no estaba definida como un delito por el Código Penal vigente. A partir de aquí se comienza a utilizar argumentos que van desde lo legal (reinterpretación de artículos del Código Penal), pasando por justificaciones morales, religiosas, científicas-médicas, para respaldar la persecución y las detenciones arbitrarias a personas homosexuales.

Los amorales se manifiestan con un cinismo extraordinario ante la ley. Son capaces de burlarse de todas las protestas y de todas las preocupaciones morales de la sociedad, por el solo hecho de que su delincuencia, no existe como tal, o con esa calificación, en el código penal. (El País, 30/o9/1959) 
El País genera una discusión para tratar de encontrar la manera de castigar e imputar a los "amorales", para encerrarlos y obligarlos a seguir un tratamiento médico y así eliminar a esta amenaza social. El asesino de Bernardo Aranda nunca fue encontrado y los artículos periodísticos y las discusiones en la prensa fueron diluyéndose hacia finales de 1959.

\section{Desarrollo de los temas seleccionados}

\subsection{Nación y familia en El País. Interpretaciones y perspectivas}

Para estudiar la construcción de la nación durante los primeros años de la dictadura, desde una perspectiva de género, hemos seleccionado dos matrices semánticas, construidas a partir de los textos publicados en El País entre los meses de setiembre y diciembre de 1959. Desde estas matrices, estudiamos la propuesta que inicialmente levantamos: cómo y de qué manera el asesinato del locutor Bernardo Aranda, se constituye en un momento de la construcción de una determinada forma de entender la nación; y también, cómo esta represión política y normalizadora en relación a usos del cuerpo puede servir como base para un entendimiento de nación durante los primeros años del stronismo. El medio fue seleccionado llevando en cuenta los siguientes criterios: i) diario de mayor antigüedad en el país, ii) estrechamente relacionado a la dictadura de Stroessner, siendo un periódico comercial no partidario. Su director y principal responsable fue secretario privado de Stroessner, iii) Como diario vespertino, fue el primero en dar la noticia del asesinato de Bernardo Aranda, el 1 de setiembre.

Los matrices fueron construidas, y los textos seleccionados, acompañando el siguiente criterio:

a. Inclusión en el texto publicado de palabras explícitas en relación a los temas seleccionados;

b. Textos que connotan (Díaz Bordenave, 2016) aspectos relacionados al tema seleccionado; o que tienen un significado latente (Merton, 1968) en relación al tema seleccionado.

c. Textos que tienen una relación directa con el asesinato del locutor Bernardo Aranda

d. Textos que, si bien no tienen una relación directa con este hecho, pueden ser interpretados de manera que el medio orienta una determinada acción o argumentación en torno al tema seleccionado.

A partir de la selección reconstruimos el recorrido de la narrativa del medio para develar cómo y de qué manera esta construcción discursiva nos remite a una idea de nación con un fuerte contenido androcéntrico. 
Si bien en la investigación como un todo seleccionamos alrededor de siete temas, o matrices semánticas, para el presente artículo apartamos dos que consideramos expresan una cierta transversalidad: a) Disciplina $y$ virilidad $y, b$ ) Juventud y música Rock and Roll.

\subsection{Disciplina, posturas viriles}

Como señalamos más arriba, la construcción de la nación paraguaya se caracterizó por un fuerte contenido androcéntrico, donde el hombre paraguayo fue el principal y único protagonista. La representación del hombre paraguayo estaba ligada a ciertas ideas y concepciones como la masculinidad, la virilidad, la hombría y el sexo fuerte, a la herencia de los padres de la nación que lucharon para liberar al Paraguay y a los cuales hay que venerar y utilizarlos de ejemplo. Durante la dictadura, los discursos desde distintas instancias del poder continuaron con esta misma dirección: el paraguayo debería ser, además, un ciudadano respetable, padre de familia, trabajador, equilibrado, honrado y honesto, y por supuesto, un buen cristiano. Hay que destacar que la muerte de Aranda sirvió para reforzar estos ideales de masculinidad y, además, para justificar la persecución y represión a personas cuya identidad de género se alejaban de la norma heterosexual.

El País, constantemente hace referencia a las "tradiciones viriles del pueblo", a "los atributos del honor viril", a "los factores morales negativos que atentan contra las viriles tradiciones paraguayas", a "la conducta moral que ennoblece la existencia de los hombres", a "nuestras tradiciones de padres de hogares paraguayos, en que deben seguir perdurando las virtudes heredadas de nuestros abuelos", entre otras expresiones similares que hacen referencia a las ideas de nación y masculinidad heredadas de las "tradiciones nacionalistas" de periodos anteriores, retomadas por el stronismo.

Frente a estas concepciones de lo masculino, se encuentra lo femenino. La representación de lo femenino no se limita solo a las mujeres, también a los hombres afeminados, los homosexuales, etc. La homosexualidad masculina es considerada como lo "otro" femenino que se contrapone a aquella idea de hombre masculino y viril que, como vemos en la narrativa utilizada por El País, se lo vincula con la perversidad, la criminalidad, la falta de moralidad y hasta lo patológico.

No están en los hogares humildes de nuestro pueblo los vesánicos conculcadores de nuestras costumbres virtuosas, los factores morales negativos que atentan contra las viriles tradiciones paraguayas, sino en los antros en que se ocultan para meditar la bajeza de sus maniobras, extender sus redes de base de dinero y de incitaciones que obran sobre la mente de los niños y de los jóvenes. (El País, 30 /og/1959) 
A partir de la muerte de Aranda, se publican una variedad de artículos que hacen referencia a la peligrosidad de los "amorales", a la amenaza que representan para el orden social y moral del país. En otra cita extraída del editorial de este medio se refleja esta situación, percibida como alarma social que sirvió para generar un ambiente de zozobra y paranoia, al mismo tiempo de justificar y legitimar la persecución a homosexuales:

Si hay hechos que verdaderamente señalan la necesidad de medidas preventivas en salvaguardia de la moral social, ellos deben servirnos para tener en cuenta que las virtudes viriles, las conductas sanas en armonía con el honor y la tradición de los hogares, tienen su defensa propia en el alma misma de nuestro pueblo, y que atento a ella, deben ser sancionadas ejemplarmente las desviaciones que señalan un brote de delincuencia que repugna a la conciencia nacional. (El País, 10/o9/1959)

La muerte de Bernardo Aranda,

[...] ha venido a actualizar este problema de carácter social, que si lo ocultáramos no haríamos sino contribuir a la propagación de un mal que atenta contra las virtudes de nuestra raza y contra las tradiciones de honorabilidad, de espectabilidad, de respeto y bien de los hogares paraguayos. (El País, 19/og/1959)

Lo que podemos ver, por lo tanto, a través de este periódico es la representación de las mujeres como el "sexo débil": sumisas y obedientes, condicionadas a ciertos espacios y con una limitada o nula posibilidad de participación política, sin derechos a reclamar. Así también la imagen de los homosexuales, los llamados "amorales", ha estado relacionada con la criminalidad, la perversión, la enfermedad mental. En definitiva, todas estas ideas consiguieron justificar y respaldar la persecución a los homosexuales y el control sobre las mujeres durante los primeros años del stronismo.

\subsection{Juventud y música Rock and Roll}

La primera información publicada el día 1 de setiembre en página 2 de este medio, recoge lo siguiente:

De acuerdo a las primeras informaciones captadas por nuestro Cronista en el lugar del triste desenlace, dan cuenta que a las 1.15 horas de la madrugada de hoy Aranda llegó a su casa. Entró y puso en el corredor su moto, según dijo la dueña de la casa, señora Lidia Álvarez. Después fue a la emisora "Comuneros" a traer un disco. Volvió a su pieza. Sintonizó su receptor y puso el disco "La Revista del Rock" Bill Haley y sus Cometas -long play- que dejó en el tocadisco. Así quedó al parecer dormido. Para dormir había cerrado bien la puerta y la ventana de su pieza. (El País, 1/o9/1959) 
Podemos observar que en esta narrativa se inserta el texto como "criterio de verdad", pues el cronista lo escribe "desde el lugar del triste desenlace", una práctica que incluye al periodismo y también a otras ciencias sociales como la antropología. Se identifica a Bernardo Aranda como un simpatizante de la música rock, al escuchar el disco de Bill Haley y sus Cometas. En esta construcción discursiva, se introduce la música que orienta un determinado comportamiento de Aranda. Sin embargo, hasta el momento la narrativa es, aparentemente, "neutra" e independiente, en el sentido del periodismo clásico.

Pocos días después, el medio publica un texto tomado del editorial de la revista La Voz de la Policía, bajo el título: Auge de la Criminalidad:

La bebida, la parranda, la patota, cuentan cada vez con más adeptos. Desde la sombra actúan los sombríos personajes del vicio, los más peligrosos enemigos de la juventud y de la adolescencia actual [...] Así, lo que en principio parece inocente diversión del rock and roll, se convierte en el primer caso hacia la caída en el abismo del vicio peor, que degrada a los hombres hasta las últimas escalas de la especie inferior.

Más adelante, el texto continúa:

Las frecuentes salidas nocturnas, el afeminamiento en el vestir, en el peinarse, y la excesiva preocupación por ciertas modas en el peinado y en el baile, son síntomas de alarma. Ningún padre se inclina a desconfiar de la virilidad del hijo, pero justamente esos padres confiados o despreocupados, son los que han afrontado los más agudos problemas. (El País, 10/o9/1959).

En estas líneas, el aparato represivo del Estado, a través de su vocero oficial, La Voz de la Policía, asocia el uso del cuerpo de una manera determinada, a personas de "dudosa conducta moral". Estas son: 1) frecuentes salidas nocturnas; 2) afeminamiento en el vestir y en el peinarse y 3) excesiva preocupación por ciertas modas en el peinado y en el baile.

En el despliegue de esta tipología y en los usos diferenciados del cuerpo de los jóvenes varones que se apartan de la norma impuesta, el discurso del poder asocia un comportamiento que denomina "vicios innombrables", "depravaciones" o que señalan caminos hacia la "criminalidad", incluyendo el rock and roll -formas de mover el cuerpo-, a esta forma "desviada" de aquella aceptada como "normal" o "natural". Aquellos jóvenes que de alguna manera son asociados como de un accionar vicioso o desviado: son depravados, tienen vicios innombrables, son de dudosa conducta moral, en fin, son criminales. Pero no solo esto, al "desconfiar de la virilidad del hijo" -obviamente todo hombre es viril y así debe ser entendido su comportamiento social-, la construcción discursiva del texto los convierte en jóvenes con problemas y esto debe ser motivo de preocupación para los padres de familia. El discurso de la autoridad es también seme- 
jante a aquel que se despliega frente a otros tipos de criminales, aquellos que poseen otros vicios innombrables, criminales: los subversivos políticos, o sea, aquellos que ejercen otra oposición a la dictadura stronista.

Al día siguiente El País publica un texto bajo el título: "108 Personas de Dudosa Conducta Moral Están Siendo Interrogadas." Como subtítulo o bajada, insertan lo siguiente: "Anoche se notó un inusitado movimiento policial. Nuestro Cronista amaneció siguiendo los Trabajos”. En el texto se desliza el siguiente párrafo:

Por de pronto, la acción policial se desarrolla de manera muy activa, como antes no se ha hecho de igual envergadura para esclarecer el misterio que rodea a la muerte del famoso locutor y bailarín de rock and roll, Bernardo Aranda. (El País, 11/og/1959)

En estas líneas ya se destaca que el medio de alguna manera acompaña la tipología impulsada por la policía: un determinado tipo de música -rock and roll-, provocaría el desvío de los jóvenes. Sin embargo, como podemos ver el temor no se extiende a las jóvenes mujeres.

Como refuerzo a esta construcción narrativa, el diario publica el mismo día y en la misma página otro texto con el siguiente título: "Ramón Aranda, padre del infortunado locutor confía en que la justicia aclarará todo”.

Su ambición, que alimentaba desde chiquilín, dice el padre, era ser un gran artista. Le gustaba cantar, bailar y tocar la guitarra. Su gusto en el vestir puede decirse que adoraba y era su encanto usar ropas que usaban los artistas del cine o algo similar a los vestidos de los vaqueros, etc. Su debilidad, agrega el padre, era preparar comedias y actuar. Sentía la sensación del ídolo que atrae y fascina a la muchedumbre que gusta del arte nativo y del rock and roll. Este estilo de baile dominaba casi a la perfección. (El País, 11 de setiembre, 1959)

El medio introduce nuevamente en su narrativa un determinado entendimiento sobre los usos del cuerpo en los jóvenes varones. Sin embargo, un aspecto que llama la atención en estas publicaciones es la ausencia de la mujer y la aparente falta preocupación del texto acerca del peligro de estos comportamientos para las jóvenes paraguayas. Llama la atención la inexistencia de temas relacionados con lesbianas en la investigación policial cubierta por El País durante esta época. Las lesbianas han estado invisibilizadas en las informaciones publicadas por los medios de prensa de la época. Entonces nos preguntamos: ¿a qué se debe esta falta de preocupación por las mujeres y las modas juveniles?

En los artículos publicados en El País, que se vinculan con el caso Aranda y con temas relacionados a la idea de nación, casi no se hace referencia al papel de las mujeres. En algunos casos, como pudimos constatar, los momentos en que se habla sobre ellas, suelen estar relacionados a mujeres que se caracterizan por 
tener comportamientos poco adecuados según los ideales de la época: la mujer como morbosa, la mujer chismosa, etc.

La chismosa es un tipo universal de mujer charlatana [...] Es el 'alto parlante humano' ambulante que recorre en su jira corrosiva todos los rincones del lomo pardo de la tierra. El fastidio, la amargura, la cólera y hasta el odio deja en los lugares donde en mala hora siempre llega. Su estela enturbia y destruye la armonía y la felicidad de los demás. Su radio de acción es amplio [...] No reconoce sexo, nacionalidad ni religión. Se ensaña con todos por igual. (El País, 25/og/1959)

Así, el lugar que se le otorga a la mujer en los espacios de poder, es prácticamente nulo. El papel de la mujer se encuentra restringido a la esfera privada, es decir, la maternidad, la familia, el hogar y todo lo que tenga que ver con las tareas reproductivas. En el País se pueden encontrar anuncios publicitarios que reflejan el lugar de la mujer en el hogar, en la cocina, con los hijos y atendiendo al marido. Otro espacio ocupado por la mujer en la sociedad percibido en El País y que se aleja del papel de madre y esposa, es el de los concursos de belleza que se caracterizan por una representación objetivada del cuerpo femenino. En la narrativa del periódico se resaltan así ciertas cualidades asociadas a la idea de mujer: por un lado, la mujer alegre, bella, sonriente, seductora, jovial, delicada, etc. y por otro lado, la mujer chismosa y maliciosa.

\section{Conclusiones}

A lo largo de los contenidos seleccionados del diario El País, fue posible observar cómo y de qué manera este medio impreso construyó los ideales de hombre y mujer necesarios para que los mismos sean parte del ideal de nación que en esos momentos la dictadura stronista (1954-1989) estaba impulsando y desarrollando. En varios momentos de esta narrativa es posible observar de manera explícita cómo y de qué manera debe ser/comportarse el hombre. Mientras, la mujer está presente más como omisión que como sujeto. Sin embargo, esta omisión tiene una gran presencia latente y simbólica. En ella se expresa, al mismo tiempo, el ideal de mujer necesario para la nación paraguaya, y que se responda a los objetivos de la dictadura. La nación es masculina, y los hombres que la componen -no se habla de mujer- deben tener comportamientos masculinos.

El discurso narrativo del medio construye, sin duda alguna, un determinado modelo de hombre y, también desde el mismo, un modelo de nación. El cuerpo de las personas está siendo intervenido, señalando qué es lo que deben hacer los jóvenes para no tener un comportamiento afeminado. La nación y el ser paraguayo se construyen y se los imagina como masculinos, siendo la virilidad una de sus características principales, lo que termina excluyendo todo lo relacionado con lo femenino, sean las mujeres u hombres afeminados. 
Se domestica el cuerpo de manera que el mismo corresponda a un imaginario de nación paraguaya. Al mismo tiempo construyen el cuerpo de una manera histórica y con esto la narrativa legitima esa mirada anclada en lo heterosexual como modelo universal. Cómo se mueve el cuerpo (baile del rock and roll), de qué manera se viste, la disposición de los cabellos al peinarse, el movimiento de la cabeza y de los brazos, etc., todo esto conforma una determinada visión sobre el cuerpo de las personas, cómo y de qué manera este cuerpo debe ser usado.

La nación es identificada con el varón viril, alejado de prácticas sodomitas, y sin mujeres. ¿Dónde debería estar ella en este ideal de nación? En el mundo doméstico, la mujer no es un sujeto político. El texto también construye subjetividades y expresa intencionalidad. La patria es universal para todos los paraguayos, como lo heterosexual, que es también la norma universal. No pueden estar separados.

Luego, la primera gran represión masiva del stronismo a poco menos de cinco años de su instalación, nos devela que por detrás de una represión a "criminales amorales", lo que está en juego es una domesticación política del cuerpo tanto de hombres como de mujeres, de manera que la emergente dictadura cívico-militar de Stroessner pueda contar con su propio imaginario de nación: masculina y heteronormativa.

Al mismo tiempo, fue posible constatar que la investigación de la muerte de Bernardo Aranda se constituyó en una de las primeras -si no la primera- gran represión masiva contra sectores que tenían comportamientos "impuros" o "desviados", o desarrollaban teorías promiscuas, sean estos homosexuales, gremios de trabajadores, estudiantes, o diversos grupos políticos de oposición a la dictadura. La gran represión que tiene como telón de fondo la investigación del caso Aranda, se constituye en el "laboratorio" de los aparatos represivos de la dictadura, sean policiales o judiciales; desde entonces, esta matriz se repitió sistemáticamente ante a la aparición de diversos sectores que asumen comportamientos promiscuos, cuestionadores o subversivos, sean éstos en el plano teórico, asimismo en la práctica cotidiana.

\section{Referencias bibliográficas}

Almada Roche, A. (2012). 108 y un quemado ¿̨Quién mato a Bernardo Aranda? Asunción: Arandura.

Bareiro, L.; Soto, C. \& Monte, M. (1994). Alquimistas. Documentos para otra historia de las mujeres. Asunción: CDE.

Bidaseca, K. (2014). Tercer feminismo: Nomadismo identitario, mestizaje y travestismo colonial. Para una genealogía de los feminismos descoloniales. En S. Borneo Funk; L. Simões Minella, \& G. de Oliveira Assis (Org.), Linguagens e narrativas. Desafios feministas (p. 233-250). Tubarao-SC: Editora Copiart. 
Bidaseca, K. \& Serra, M. (2014). Políticas de lo mínimo: Genealogías coloniales en los mapas del sur. Estudos Feministas, 22(2): 617-625.

Carbone, R. (2014). Puntos de fuga. Asunción: ServiLibro.

Castro Gómez, S. \& Grosfoguel, R. (2007). El giro decolonial, Bogotá: P. Universidad Javeriana - Ediciones del Hombre - Universidad Central.

Céspedes, R. L. (2016). Imaginarios, memoria y tiempo en Paraguay, Asunción: Flacso-Paraguay.

Céspedes, R. \& Paredes, R. (2004). La resistencia armada al stronismo: panorama general. En Novapolis, 8:4-26.

Comisión Verdad y Justicia (2008). Informe final. Asunción. Recuperado de http:// bit.ly/2w2jNWM.

Corvalan, V. (1994). Feminismo, la causa de la mujer en el Paraguay. En Bareiro, L.; Soto, C. \& Monte, M. Alquimistas. Documentos para otra historia de las mujeres, Asunción: CDE.

Coronel, J. (2013). El movimiento sindical y su resistencia en la consolidación del régimen stronista 1955-1959. Novapolis, 6:29-47.

Costa Lima, C. (2014). Feminismos descoloniais para além do humano. Estudos Feministas, 22(3): 929-934

Cuevas, C. (2015). Corpos abjetos e amores malditos: homossexualidade, anonimato e violência institucional na ditadura stronista em Assunção, 1959. Tesis de Maestría. Universidad Federal de Parana, Curitiba, Brasil.

Dávalos, S. (2007 [1907]). Humanismo. Asunción: CDE.

Díaz Bordenave, J. (2016). Comunicación. Asunción: Arandura.

Dure, E. (2012). Asumir ser Trans en Paraguay. Informe de Consultoría, Asunción: Luna Nueva.

Dure, V. \& Silva, A. (2004). Frente Unido de Liberación Nacional (1959-1965), guerra de guerrillas como guerra del pueblo. Novapolis 8:60-90.

Falabella, F. (2012). Ciudadanías sexuales y democracia. El movimiento LGTBI en Asunción. Novapolis 5:55-76.

Junta de Gobierno (s/f). El reencuentro partidario. Imprenta Nacional: Sub-Secretaría de Prensa.

Lugones, M. (2014). Rumbo a un feminismo descolonial. Revista de Estudios Feministas, 22(3): 935-952.

Lugones, M. (2010). Colonialidad y género. En H. Cairo \& R. Grosfoguel, Descolonizar la modernidad, descolonizar Europa, Madrid: IEPALA.

Mignolo, W. (2003). Historias locales/Diseños globales, Madrid: Akal.

Merton, R. K. (1968). Manifest and Latent functions. En R. K. Merton, Social Theory and Social Structure, New York: Free Press.

Neri Farina, B. (2010). El siglo perdido. Asunción: ServiLibro.

Nuñez, A. (2001). 108 y un quemado. Asunción: Arandura.

O'Leary, J. E. (1992). Historia de la Guerra de la Triple Alianza, Asunción: Carlos Schauman. Original de 1911, en el Álbum Gráfico de A. López Decoud. 
Orué Pozzo, A. (2007). Periodismo en Paraguay. Estudios e interpretaciones. Asunción: Arandura.

Preciado, B. (2008). Testo Yonqui. Madrid: Espasa-Calpe

Quijano, A. (2000). Colonialidad del poder, eurocentrismo y América Latina, en E. Lander (Comp.), La Colonialidad del saber, Buenos Aires: Clacso.

Scott, J. W. (1996). El género: una categoría útil para el análisis histórico. En Lamas, M. El género: la construcción cultural de la diferencia sexual. México: PUEG. $\mathrm{P}$ 265-302.

Segato, R. (2014). El sexo y la norma: frente estatal, patriarcado, desposesión, colonialidad. Revista de Estudios Feministas, 22(2): 593-616.

Silveira, T. (1994). Documentos. En L. Bareiro, C. Soto \& M. Monte, Alquimistas. Asunción: CDE.

Szokol, E. (2013). 108. Ciento ocho. Asunción: Arandura.

Villalba, V. (2009a). Quiero que me digan travesti. Informe de Consultoría. Asunción: OIT-PEC.

Villalba, V. (2009b). Frente a la violencia: educar en igualdad. Informe de Consultoría. Asunción: MEC-AECID-Igualdad.

Wittig, M. (2006). El pensamiento heterosexual y otros ensayos. Madrid: Egales. 